\title{
Study of Interactions Between Individual Phenolics of Aronia with Barley $\beta$-Glucan
}

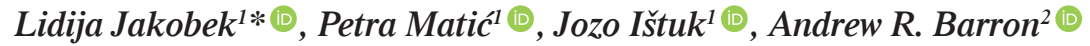 \\ ${ }^{\prime}$ Josip Juraj Strossmayer University of Osijek, Faculty of Food Technology Osijek, Franje Kuhača 18, Osijek, Croatia \\ ${ }^{2}$ Yale University, Department of Statistics and Data Science, 24 Hillhouse Avenue, New Haven, CT 06511, USA
}

Key words: adsorption isotherms, adsorption capacity, non-linear models, chokeberry, interactions

Beneficial effects of aronia phenolics are determined by their interactions with dietary fibers, such as $\beta$-glucan. The aim of this research was to study interactions between aronia phenolics and $\beta$-glucan by investigating the adsorption process. Phenolic compounds were extracted from aronia, analyzed using high-performance liquid chromatography, and adsorbed onto $\beta$-glucan at $\mathrm{pH}$ 1.5. The adsorption data were modeled by using Langmuir, Dubinin-Radushkevich, and Hill isotherms with a novel non-linear regression developed especially for adsorption isotherms. Aronia phenolics adsorbed onto $\beta$-glucan in amounts 31-250 mg/g (individual anthocyanins), 44-123 mg/g (individual flavonols), and $51 \mathrm{mg} / \mathrm{g}$ (neochlorogenic acid). The correlation between adsorption capacities and phenolic content was high $\left(\mathrm{r}^{2}=0.94\right)$, which suggested that the adsorption might be concentration dependent. Modeling with a novel non-linear regression allowed more precise determination of adsorption isotherm parameters. Furthermore, there was a correlation between maximum adsorption capacities predicted by models and measured adsorption capacities $\left(\mathrm{r}^{2}=0.76, \mathrm{r}^{2}=0.81\right.$ and $\mathrm{r}^{2}=0.34$ for Langmuir, Dubinin-Radushevich, Hill isotherms, respectively). The suggested bonds involved in interactions are non-covalent bonds (H bonds, Van der Waals forces). Principal component analysis showed that anthocyanins, flavonols, and phenolic acids could differently behave in the adsorption process, which could be due to differences in the chemical structures (ionic nature of anthocyanins, nonionic nature of flavonols and phenolic acids at low $\mathrm{pH}$ ). In conclusion, aronia phenolics interacted with $\beta$-glucan by adsorbing onto its surface, and the novel modeling developed by our team was helpful in the interpretation of this process. Interactions should be further studied due to their importance for the beneficial effects of aronia.

\section{INTRODUCTION}

Aronia (Aronia melanocarpa) (also called chokeberry) is a fruit with a high content of phenolics belonging to different phenolic subgroups: anthocyanins, flavonols, phenolic acids, and flavan-3-ols [Denev et al., 2019; Sidor et al., 2019]. Due to these large contents, potential positive bioactivities of aronia phenolics have been investigated, including their beneficial effects on hypertension, diabetes, and hypercholesterolemia [Sidor et al., 2019]. Aronia phenolics might reduce the risk of a metabolic syndrome development [Sidor et al., 2019] and inhibit the activity of pancreatic lipase, which can be helpful in obesity prevention [Sosnowska et al., 2018]. Due to these beneficial effects, aronia phenolics are still being investigated.

Phenolic compounds can interact with carbohydrates, proteins or lipids from food in the digestive tract [Jakobek, 2015], and this interaction can lead to many effects, one of which is the influence on the amount of phenolics accessible for absorption in the digestive tract (bioaccessibility) [Palafox-Carlos et al., 2011; Renard et al., 2017; Saura-Calixto, 2011]. Moreover, certain food components, like dietary fibers, which are indigestible in the small intestine and ferment in the large intestine, can interact with phenolics, which might result in the "carrying" of these compounds to the lower parts of the digestive tract. Herein, phenolics might be released and elicit their beneficial activities [Palafox-Carlos et al., 2011]. Since dietary fibers have the potential to "carry" bioactive components through the digestive tract, they have already been investigated as delivery systems for various phenolics [Tang et al., 2020]. Due to the importance of phenolic-dietary fiber interactions, they are still being investigated.

Interactions between phenolic compounds and dietary fibers can be investigated in vitro through the study of the adsorption process, during which a substance from a gas or liquid is being adsorbed onto an adsorbent. The amount of the substance adsorbed can be compared to the amount of the substance non-adsorbed, and their relationship is called an adsorption isotherm [Foo \& Hameed, 2010; Limousin et al., 2007]. The data in adsorption isotherm graphs can be modeled with various equations, some of which are Langmuir, Freundlich, Dubinin-Radushkevich, or Hill adsorption isotherms [Al-Ghouti \& Da'ana 2020; Foo \& Hameed 2010; Limousin et al., 2007]. The approach to study interactions between phenolic

\footnotetext{
* Corresponding Author:

e-mail: lidija.jakobek@ptfos.hr (L. Jakobek)
} 
compounds and dietary fibers through the adsorption process has been applied previously for phenolics and cellulose [Liu et al., 2017], phenolics and starch nanoparticles [Liu et al., 2016], or phenolics and cell wall constituents [Le Bourvellec et al., 2004; Le Bourvellec \& Renard, 2005].

$\beta$-Glucans are soluble dietary fibers found in cereals like oats or barley with many potentially positive effects on human health [Mäkelä et al., 2020]. Since they show beneficial effects and they are dietary fibers, $\beta$-glucans are good candidates for interacting with phenolics and carrying them through the digestive tract, as proved successful with various bioactive compounds [De Smet et al., 2013; Hwang et al., 2018; Lee et al., 2019; Li \& Cheung, 2019]. Hence, the interactions of $\beta$-glucans with phenolic compounds have attracted interest to know the fate of these compounds in the digestive tract after their interactions, and, in particular, whether the phenolics are carried to the lower parts of the digestive tract by $\beta$-glucans where they might show beneficial effects. Interactions between $\beta$-glucan and tea phenolics [Gao et al., 2012; Wu et al., 2011a,b] or apple phenolics [Jakobek et al., 2020a] have been studied via the adsorption process. But, to the best of our knowledge, there have been no studies of the interactions between aronia phenolics and $\beta$-glucan through adsorption. Many studies have shown that aronia has a very high content of phenolics, especially anthocyanins [Denev et al., 2019; Sidor et al., 2019], which differentiates it from other fruit and raises the possibility of their different behavior in the adsorption/interaction with $\beta$-glucan. Furthermore, since aronia shows the already-mentioned potential beneficial effects [Sidor et al., 2019; Sosnowska et al., 2018], as well as lowers blood pressure [Hellström et al., 2010] and reduces plasma cholesterol [Kim et al., 2013], this fruit offers a high potential for being used as a dietary supplement. This makes it important to know the effects of aronia on the human health. But much remains unknown about the fate of aronia phenolics in the digestive tract. The investigation of interactions between aronia phenolics and dietary fibers ( $\beta$-glucan) can contribute to the knowledge in one part of this landscape of unknowns - the possible bonding of aronia phenolics to fibers, and the potential of $\beta$-glucan for carrying the aronia phenolics through the digestive tract.

The aim of this study was to investigate interactions between aronia phenolics and $\beta$-glucan from barley through the adsorption process. Aronia phenolics were extracted and analyzed with reversed-phase high-performance liquid chromatography (RP-HPLC). After conducting the adsorption process between aronia phenolics and $\beta$-glucan, the adsorption data were modelled with adsorption isotherm equations (Langmuir, Dubinin-Radushkevich, and Hill) using a novel, improved non-linear regression, a process developed by our team to fit and to interpret adsorption isotherms with more precision.

\section{MATERIALS AND METHODS}

\section{Chemicals}

Potassium chloride was purchased from Gram mol (Zagreb, Croatia), hydrochloric acid from Carlo Erba (Val-deReuil, France), $\beta$-D-glucan from barley, chlorogenic acid, quercetin 3-glucoside, quercetin 3-rutinoside from Sigma-Aldrich (St. Louis, MO, USA), and cyanidin 3-galactoside chloride, cyanidin 3-glucoside chloride, quercetin 3-O-galactoside from Extrasynthese (Genay, France). Orto-phosphoric acid (85\% HPLC-grade), methanol, and acetonitrile (HPLC grade) were from Fluka (Buchs, Switzerland), J.T. Baker (Gliwice, Poland), and Fisher Scientific (Loughborough, UK), respectively.

\section{Samples}

Aronia berries (around $1 \mathrm{~kg}$ ) were harvested from a local producer in the town of Orahovica, Croatia, and frozen at $-18^{\circ} \mathrm{C}$. Around $300 \mathrm{~g}$ of aronia were grinded and homogenized with a stick blender. Then, $0.2 \mathrm{~g}$ of homogenized aronia were weighed into a plastic tube, $1.5 \mathrm{~mL}$ of $80 \%(\mathrm{v} / \mathrm{v})$ methanol in water was added, the sample was vortexed, extracted for 15 min (ultrasonic water bath) (RK 100, Berlin, Germany), and then centrifuged for $10 \mathrm{~min}$ at $6739 \times \mathrm{g}$ (Eppendorf, Hamburg, Germany). The extract was pipetted into a separate plastic tube. The residue was extracted one more time with the same procedure using $0.5 \mathrm{~mL}$ of $80 \%(\mathrm{v} / \mathrm{v})$ methanol. The two extracts were then combined to get a measured final volume of the extract of about $2 \mathrm{~mL}$. The same procedure was repeated to get a second parallel extract of aronia. Extracts were filtered through a PTFE syringe filter with $0.45 \mu \mathrm{m}$ pores and then analyzed on the HPLC system two times to determine the content of phenolics before adsorption $(n=4)$.

\section{Adsorption}

A $\beta$-glucan solution $(190 \mathrm{mg} / \mathrm{L})$ was prepared by dissolving $\beta$-glucan in distilled water heated at $80^{\circ} \mathrm{C}$. Since anthocyanins make a high portion of total aronia phenolics and they are stable at low $\mathrm{pH}$, a $\mathrm{pH} 1.5$ was chosen for the adsorption process. This enabled us to correctly determine anthocyanins in the adsorption process. Also, a low $\mathrm{pH}$ corresponds to the part of the digestive process. In accordance to this fact, a solution of $\mathrm{pH} 1.5$ was prepared from $\mathrm{HCl}$ and $\mathrm{KCl}$ solutions $(0.1 \mathrm{M})$ to be used in the adsorption process. For the adsorption experiment, the reaction solution contained $\beta$-glucan $(15 \mathrm{mg} / \mathrm{L})$, an aliquot of aronia extract $(50 \mathrm{~mL})$, and the rest of the volume to the total volume of $1 \mathrm{~mL}$ was a buffer solution at $\mathrm{pH} 1.5$. The mass ratio of total phenolics of the aronia extract to $\beta$-glucan was $4 \mathrm{mg} / 1 \mathrm{mg}$. The vessel with the reaction solution was then placed onto a shaker for $3 \mathrm{~h}$, at room temperature. After adsorption, the reaction solution was centrifuged for $10 \mathrm{~min}$ at $6739 \times \mathrm{g}$ (Eppendorf, Hamburg, Germany). An aliquot of $500 \mathrm{~mL}$ was taken, filtered through a PTFE syringe filter $0.45 \mu \mathrm{m}$, and injected into the HPLC system for the determination of un-adsorbed phenolics $\left(c_{\mathrm{e}}\right.$ in $\left.\mathrm{mg} / \mathrm{L}\right)$. The $c_{\mathrm{e}}$ value was also recalculated in $\mathrm{mg}$. Adsorption capacity $\left(q_{\mathrm{e}}\right)$ (mg of phenolics adsorbed onto $\mathrm{g}$ of $\beta$-glucan) was calculated, by the following equation which is a rearrangement of the expression of the conservation of mass (the amount adsorbed plus the amount not adsorbed equals the initial amount of phenolics):

$$
q_{e}=\frac{\left(c_{0}-c_{e}\right) V_{m}}{\gamma_{a} V_{a}}
$$


where: $c_{0}$ is the initial phenolic concentration in the reaction solution $(\mathrm{mg} / \mathrm{L}), c_{\mathrm{e}}$ is the phenolic concentration in the reaction solution after adsorption or un-adsorbed phenolics $(\mathrm{mg} / \mathrm{L}), V_{\mathrm{m}}$ is the total volume of a reaction solution $(\mathrm{L})$, $\gamma_{\mathrm{a}}$ is the $\beta$-glucan concentration $(\mathrm{g} / \mathrm{L})$, and $V_{\mathrm{a}}$ is the volume of added $\beta$-glucan in a reaction solution (L). The modeling of the adsorption process with adsorption isotherm equations requires the data from adsorption at varying mass ratios of total phenolics from aronia to $\beta$-glucan. That is why the adsorption was performed using five various volumes of aronia extract aliquots in the range of 50 to $150 \mathrm{~mL}$ (mass ratio of total phenolics from aronia/ $\beta$-glucan ranged from $4 / 1$ to $9 / 1 \mathrm{mg} / \mathrm{mg}$ ). Adsorption experiment was performed once with each of the two prepared aronia extracts, and un-adsorbed phenolics were determined two times $(n=4)$.

\section{RP-HPLC analysis}

Aronia phenolics before and after adsorption were analyzed by using an 1260 Infinity II HPLC system (Agilent Technology, Santa Clara, CA, USA) with a quaternary pump, a photodiode array (PDA) detector, a vialsampler, a Poroshell 120 EC C- 18 column $(4.6 \times 100 \mathrm{~mm}, 2.7 \mathrm{~mm})$ with a Poroshell 120 EC-C18 $4.6 \mathrm{~mm}$ guard-column. Phenolic compounds were separated by using $0.5 \%(v / v) \mathrm{H}_{3} \mathrm{PO}_{4}$ (mobile phase A), and $100 \%$ acetonitrile (mobile phase B) with the following gradient: $5 \%$ B 0 min, 11\% B 5 min, $15 \%$ B $7.5 \mathrm{~min}, 17.5 \%$ B $17.5 \mathrm{~min}, 20 \%$ B $20 \mathrm{~min}, 30 \%$ B $30 \mathrm{~min}, 70 \%$ B $32 \mathrm{~min}$, $70 \%$ B $34 \mathrm{~min}, 5 \%$ B $36 \mathrm{~min}, 5 \%$ B $38 \mathrm{~min}$. The flow rate was set to $0.8 \mathrm{~mL} / \mathrm{min}$. Stock solutions of anthocyanin standards were prepared in $0.1 \% \mathrm{HCl}$ in methanol. Flavonol and phenolic acid stock solutions were prepared in $100 \%$ methanol. Five dilutions of standards (10 to $100 \mathrm{mg} / \mathrm{L}$ ) were analyzed to plot calibration curves ( $r^{2} 0.9939$ to 0.9995$)$, which were used to quantify phenolics. Limits of detection (LOD) and limits of quantification (LOQ) were as follows: cyanidin 3-glucoside $(0.24$ and $0.74 \mathrm{mg} / \mathrm{L})$, cyanidin 3-galactoside $(0.22$ and $0.68 \mathrm{mg} / \mathrm{L})$, chlorogenic acid $(0.95$ and $2.88 \mathrm{mg} / \mathrm{L})$, quercetin 3-glucoside $(0.25$ and $0.74 \mathrm{mg} / \mathrm{L})$, quercetin 3 -rutinoside $(0.32$ and $0.97 \mathrm{mg} / \mathrm{L})$, and quercetin 3 -galactoside $(0.10$ and $0.32 \mathrm{mg} / \mathrm{L})$. Precision expressed as the coefficient of variation was between 3.3 and $18.8 \%$. Identification was done by comparing UV-Vis spectrum and retention times of phenolic standards with those of peaks on the chromatogram of the aronia extract. Additionally, extracts were spiked with phenolic standards to confirm the identification. Neochlorogenic acid, cyandin 3-arabinoside, and cyanidin 3-xyloside were tentatively identified with the help of literature data [Sosnowska et al., 2018] and quantified by using the calibration curve of chlorogenic acid and cyanidin 3-glucoside. The content of individual phenolics was expressed in mg per $\mathrm{kg}$ of aronia fresh weight (FW).

\section{Adsorption isotherms}

Experimental data $q_{\mathrm{e}}$ and $c_{\mathrm{e}}$ were modeled with Langmuir, Dubinin-Radushkevich, and Hill isotherm equations explained further in the text:

$q_{e}=\frac{q_{m} K_{L} c_{e}}{1+K_{L} c_{e}}($ Langmuir isotherm) $q_{e}=q_{s} \exp \left(-\beta \varepsilon^{2}\right)$ (Dubinin-Radushkevich isotherm)

$q_{e}=\frac{q_{m} c_{e}^{n_{H}}}{K_{D}+c_{e}^{n_{H}}}($ Hill isotherm $)$

The improved non-linear regression was used for modeling. The code for improved non-linear regression was written in the $\mathrm{R}$ programming language by our group and used for data modeling in our recent papers [Jakobek et al., 2020a,b].

\section{Statistical analysis}

The contents of phenolics in aronia were based on two parallel extracts, each measured twice $(n=4)$. Adsorption experiment was done once with each of the two aronia extracts. Un-adsorbed phenolics after the adsorption were measured twice $(n=4)$, and two mean values of un-adsorbed phenolics were created. Modeling of the adsorption data mean values $\left(q_{\mathrm{e}}\right.$ and $\left.c_{\mathrm{e}}\right)$ was conducted by using the R program. The standard error $(S E)$ was calculated:

$S E=\sqrt{\frac{\left(\sum_{i=1}^{n}\left(q_{e, \text { measured }}-q_{e, \text { model }}\right)^{2}\right)}{(n-a)}}$

where: $q_{\mathrm{e}, \text { measured }}$ and $q_{\mathrm{e} \text {,model }}$ are the measured $q_{\mathrm{e}}$ and the $q_{\mathrm{e}}$ calculated by the model, respectively, $n$ is the total number of data points, and $a$ is the number of parameters of the model. Principal component analysis, analysis of variance, and post-hoc Tukey test were used to find differences between the results using Minitab (Minitab LLC., State College, PA, USA).

\section{RESULTS AND DISCUSSION}

\section{Phenolic profile of aronia}

Eight phenolic compounds were separated and tentatively identified in the aronia extracts (Table 1, Figure 1). Four of them were anthocyanins (cyanidin 3-galactoside, cyanidin 3-glucoside, cyanidin 3-arabinoside, and cyanidin 3-xyloside), three were flavonols (quercetin 3-rutinoside, quercetin 3-galactoside, and quercetin 3-glucoside), and one was phenolic acid (neochlorogenic acid). Anthocyanins showed their maxima in the UV-Vis spectrum at 280 and 516 to $518 \mathrm{~nm}$, which is typical of anthocyanins. Three flavonols showed their maxima in the UV-Vis spectrum at 254-266 nm and 354-356 nm, a typical spectrum of flavonols. Neochlorogenic acid had an UV-Vis maximum at $320 \mathrm{~nm}$. The UV-Vis spectra agree with those of authentic standards and with those from literature [Sosnowska et al., 2018]. Anthocyanins, flavonols, and phenolic acids were present in the total contents of 5905, 1707, and $550 \mathrm{mg} / \mathrm{kg} \mathrm{FW}$ (Table 1), which are similar to literature data [Denev et al., 2019].

\section{Adsorption}

The adsorption was conducted first with $50 \mathrm{~mL}$ of aronia extract, and the adsorption capacities of individual phenolics $\left(q_{\text {e.measured }}\right)$ are shown in Figure 2. Cyanidin 3-galactoside and cyanidin 3-arabinoside adsorbed in significantly higher amounts than cyanidin 3-xyloside and cyanidin 3-glucoside 
TABLE 1. Contents of individual phenolics in aronia and maxima of UV-Vis spectra $\left(\lambda_{\max }\right)$ of identified compounds.

\begin{tabular}{lcc}
\hline Phenolics & $\begin{array}{c}\text { Content } \\
(\mathrm{mg} / \mathrm{kg} \mathrm{FW})\end{array}$ & $\begin{array}{c}\lambda_{\max } \\
(\mathrm{nm})\end{array}$ \\
\hline & Anthocyanins \\
\hline Cyanidin 3-galactoside & $3525 \pm 470^{\mathrm{a}}$ & 280,516 \\
Cyanidin 3-glucoside & $210 \pm 0^{\mathrm{c}}$ & 280,516 \\
Cyanidin 3-arabinoside* & $1838 \pm 261^{\mathrm{b}}$ & 280,516 \\
Cyanidin 3-xyloside* & $332 \pm 19^{\mathrm{c}}$ & 280,518 \\
Total & $5905 \pm 750$ & \\
\hline & Flavonols & 266,356 \\
\hline Quercetin 3-rutinoside & $878 \pm 148^{\mathrm{c}}$ & 254,354 \\
Quercetin 3-galactoside & $473 \pm 84^{\mathrm{c}}$ & 254,356 \\
Quercetin 3-glucoside & $356 \pm 60^{\mathrm{c}}$ \\
Total & $1707 \pm 292$ & 320 \\
\hline & Phenolic acids \\
\hline Neochlorogenic acid* & $550 \pm 75^{\mathrm{c}}$ & \\
\hline TOTAL & $8162 \pm 1117$ & \\
\hline
\end{tabular}

Analysis of variance showed that not all means $(n=4)$ were equal $(\mathrm{p}=0.000)$. Tukey pairwise comparisons were done at a significance level of 0.05 . Means that do not share a letter are significantly different. * tentatively identified. FW-fresh weight.

$(250,175,51$, and $31 \mathrm{mg} / \mathrm{g}$, respectively). In the flavonol subgroup, quercetin 3-rutinoside showed a higher adsorption capacity in comparison to galactoside and glucoside of quercetin $(123,53$ and $44 \mathrm{mg} / \mathrm{g}$, respectively) but those differences were not statistically significant. Neochlorogenic acid adsorbed in the amount $51 \mathrm{mg} / \mathrm{g}$. The adsorption capacities of phenolics agree with literature data. Namely, phenolics extracted from tea adsorbed onto $\beta$-glucan from 0.7 to $40 \mathrm{mg} / \mathrm{g}$, and a mixture of pure standards of phenolics from tea from 156 to $405 \mathrm{mg} / \mathrm{g}$ [Gao et al., 2012]. At different $\mathrm{pH}$ values, tea phenolic compounds were adsorbed by $\beta$-glucan up to $116 \mathrm{mg} / \mathrm{g}$ [Wu et al., 2011a]. Phenolic compounds adsorb onto cellulose too. Cyanidin 3-glucoside, ferulic acid, and catechin adsorbed onto cellulose up to 215,56 , and $102 \mathrm{mg} / \mathrm{g}$, respectively [Phan et al., 2016]. Various phenolics (cyanidin 3-glucoside, catechin, ferulic acid, chlorogenic acid, and gallic acid) adsorbed onto cellulose up to $600 \mathrm{mg} / \mathrm{g}$ [Phan et al., 2015]. Similar amounts of phenolics were adsorbed by cell wall material (cyanidin 3-glucoside, ferulic acid, and catechin around 600, 150, and $400 \mathrm{mg} / \mathrm{g}$, respectively [Phan et al., 2017]). Furthermore, individual phenolics adsorbed onto $\beta$-glucan in higher amounts if they were present in the extract in a higher content, which is visible in the diagram $q_{\text {e.measured }} v s$ individual phenolics content $(\mathrm{mg} / \mathrm{kg} \mathrm{FW})$ (Figure 3). The correlation was high $\left(\mathrm{r}^{2}=0.94\right)$. Accordingly, it can be suggested that the adsorption was concentration dependent. Phenolic compounds present in higher concentrations in the environment around $\beta$-glucan (cyanidin 3-galactoside and cyanidin 3-arabonoside) were

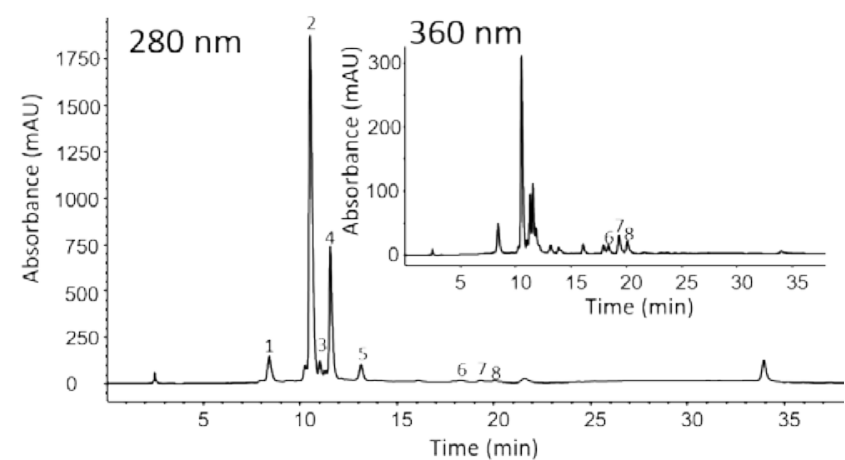

FIGURE 1. The chromatogram of aronia extract scaned at 280 and $360 \mathrm{~nm}$ with identified phenolics. Peak assignment $1^{*}$ - neochlorogenic acid, 2 - cyanidin 3 -galactoside, 3 - cyanidin 3 -glucoside, $4^{*}$ - cyanidin 3 -arabinoside, $5^{*}$ - cyanidin 3 -xyloside, 6 - quercetin 3 -rutinoside, 7 - quercetin 3 -galactoside, 8 - quercetin 3 -glucoside ( ${ }^{*}$ - tentatively identified).

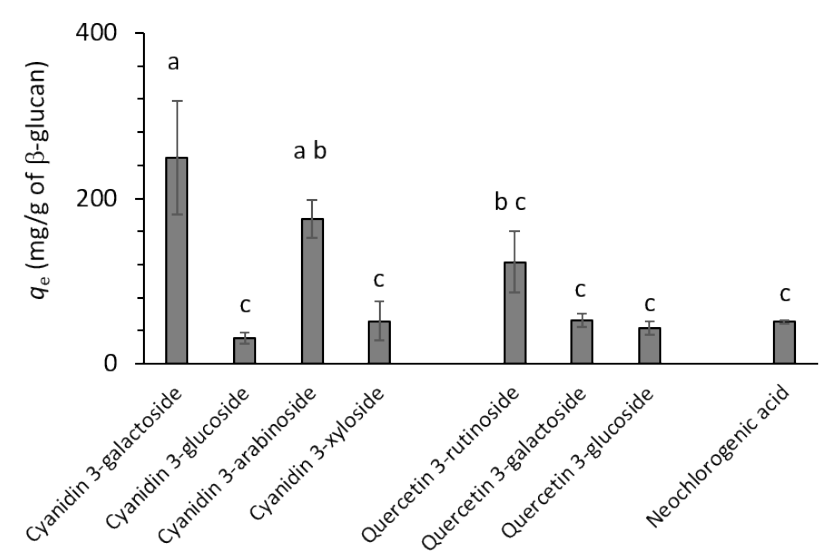

FIGURE 2. The adsorption capacity of individual aronia phenolics onto $\beta$-glucan, $q_{\mathrm{e}}$ (mass ratio of total aronia phenolics to $\beta$-glucan $-4 / 1$ ) at $\mathrm{pH}$ 1.5. Analysis of variance showed that not all means were equal $(p=0.001)$. Tukey pairwise comparisons were done at a significance level of 0.05 . Means that do not share a letter are significantly different.

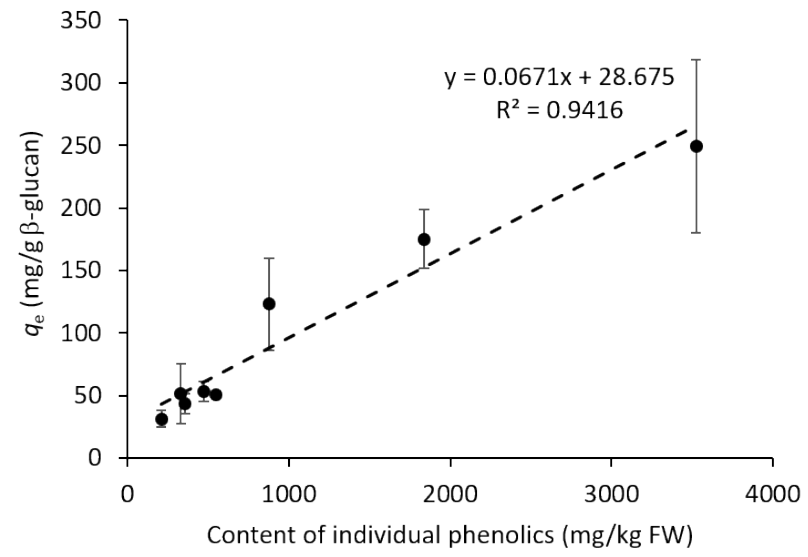

FIGURE 3. The correlation between the adsorption capacities of individual phenolics, $q_{\mathrm{e}}$ (mg/g $\beta$-glucan), and their content in the aronia extract $(\mathrm{mg} / \mathrm{kg}$ of fresh weight $(\mathrm{FW}))$. The data for $q_{\mathrm{e}}$ were obtained in the adsorption experiment with mass ratio of total aronia phenolics to $\beta$-glucan - 4/1, at $\mathrm{pH} 1.5$. 
adsorbed by $\beta$-glucan in higher amounts, and those present in lower concentrations (cyanidin 3-xyloside, cyanidin 3-glucoside, flavonols, and neochlorogenic acid) were adsorbed in lower amounts. This agrees with the study of Phan et al. [2015] who investigated the adsorption of various phenolics onto cellulose and suggested that the adsorption capacity depended on the available phenolic molecules in the aqueous solution.

\section{Adsorption isotherms}

The adsorption experiment was conducted with several different initial concentrations of the aronia extract, which enabled determining more $q_{\text {e,measured }}$ for each phenolic compound. Those values were modelled in the $q_{\mathrm{e}} v s c_{\mathrm{e}}$ diagrams with equations of Langmuir, Dubinin-Radushkevich, and Hill isotherms. The novel, improved non-linear regression was used for modeling. The improved modelling can be explained by first understanding how $q_{\text {e,measured }}$ values behave in $q_{\mathrm{e}}$ vs $c_{\mathrm{e}}$ diagram. If there are multiple values of $q_{\text {e,measured }}$ for one initial phenolic concentration, those multiple $q_{\text {e.measured }}$ values will lie on a diagonal line in the $q_{\mathrm{e}} v s c_{\mathrm{e}}$ diagram. This is due to the mass balance equation (Eq. 1) as explained in our previous paper [Jakobek et al., 2020b]. With a naive use of traditional non-linear regression, the $q_{\text {e,model }}$ is fitted to $q_{\text {e.measured }}$ to minimize the squares of vertical error, associated with a presumption of a model value of $c_{\mathrm{e}}$ matching its measured value. In contrast, for the improved non-linear modelling, the novelty is that the $q_{\mathrm{e} \text {,model }}$ is fitted together with its corresponding $c_{\mathrm{e}}$ on the diagonal line, where the $q_{\text {e.measured }}$ values are positioned with their corresponding $c_{\text {e,measured }}$. This is the proper statistical modeling that recognizes that both $q_{\mathrm{e}}$ and $c_{\mathrm{e}}$ are measured values in response to the initial amounts with exact negative correlation in their measurements due to the mass balance. We used this improved way of non-linear regression in our recent paper [Jakobek et al., 2020a]. An example of data modelled with the improved regression is shown in Figure 4. In the modelling of $q_{\mathrm{e} \text {,measured }}$ data for cyanidin 3-arabinsoide, an improved non-linear regression gave a predicted $q_{\text {e,model }}$ (special curve point) on a diagonal line where $q_{\text {e,measured }}$ data are positioned (Figure 4). It can be seen that the improved modeling differs from that of customary modeling that fits the data in a standard way on the vertical line. Namely, the improved modeling gave lower standard errors (SE) in comparison to standard modelling. Indeed, the improved non-linear regression modeled the data in a better way, with lower SE. Lower SE allowed us to suggest that the improved non-linear regression ensures better prediction of adsorption isotherm parameters and, therefore, a more precise description of the adsorption process.

\section{Langmuir isotherm}

The Langmuir isotherm describes a monolayer adsorption onto the surface of an adsorbent. The sites on the adsorbent where the adsorption takes place are limited, identical and energetically independent [Limousin et al., 2007]. The Langmuir equation is described by already mentioned equation (Eq. 2).
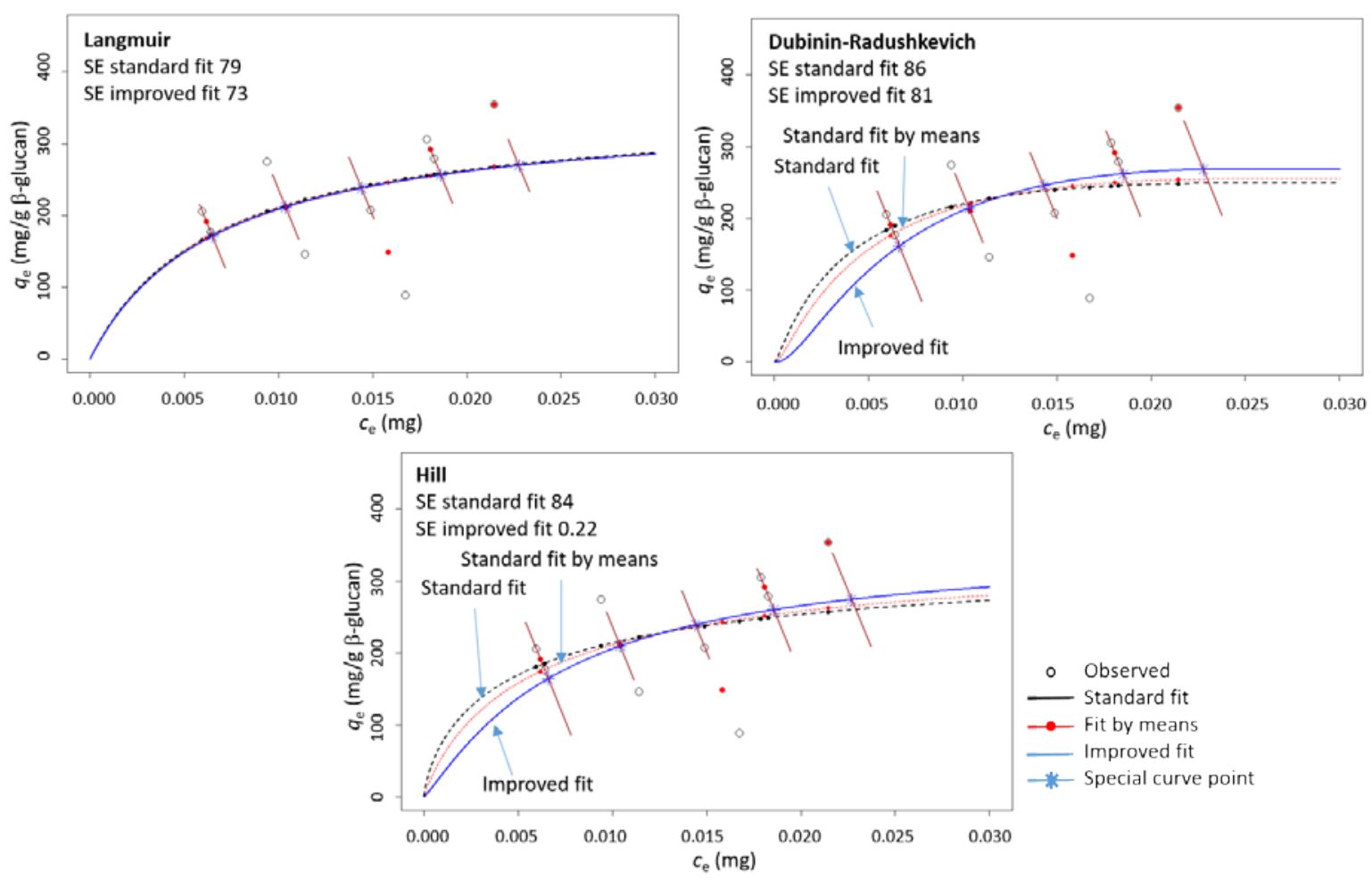

FIGURE 4. Modeling of adsorption capacity, $q_{\mathrm{e}}$ (mg/g of $\beta$-glucan), $v s$ un-adsorbed amount of cyanidin 3-arabinoside, $c_{\mathrm{e}}$ (mg), by using the novel non-linear regression in R programing language. Curves were obtained for standard fit of measured values (black curve), standard fit of measured mean values (red curve), and a novel improved fit (blue curve). SE; standard error. 
TABLE 2. Parameters of Langmuir, Dubinin-Radushkevich, and Hill adsorption isotherms obtained by the improved non-linear modeling of adsorbed phenolics from aronia onto $\beta$-glucan.

\begin{tabular}{|c|c|c|c|c|c|c|c|c|c|c|c|}
\hline \multirow[b]{2}{*}{ Phenolics } & \multicolumn{3}{|c|}{ Langmuir } & \multicolumn{4}{|c|}{ Dubinin-Radushkevich } & \multicolumn{4}{|c|}{ Hill } \\
\hline & $\begin{array}{c}q_{\mathrm{m}} \\
(\mathrm{mg} / \mathrm{g})\end{array}$ & $\begin{array}{c}K_{\mathrm{L}} \\
(1 / \mathrm{mg})\end{array}$ & SE & $\begin{array}{c}q_{\mathrm{s}} \\
(\mathrm{mg} / \mathrm{g})\end{array}$ & $\begin{array}{c}E \\
(\mathrm{~J} / \mathrm{mol})\end{array}$ & $\begin{array}{c}c_{\mathrm{s}} \\
(\mathrm{mg})\end{array}$ & SE & $\begin{array}{c}q_{\mathrm{m}} \\
(\mathrm{mg} / \mathrm{g})\end{array}$ & $n_{\mathrm{H}}$ & $\begin{array}{c}K \\
(\mathrm{mg})\end{array}$ & SE \\
\hline \multicolumn{12}{|c|}{ Anthocyanins } \\
\hline Cyanidin 3-galactoside & 356 & 193 & 105.0 & 309 & 8760 & 0.0600 & 104.0 & 554 & 0.10 & 0.0052 & 5.2 \\
\hline Cyanidin 3-glucoside & 100 & 979 & 13.7 & 79 & 1816 & 0.0025 & 14.9 & 100 & 1.89 & 0.0012 & 0.1 \\
\hline Cyanidin 3-arabinoside & 350 & 147 & 73.1 & 269 & 3248 & 0.0250 & 81.2 & 350 & 1.14 & 0.0073 & 0.2 \\
\hline Cyanidin 3-xyloside & 238 & 353 & 33.4 & 190 & 4889 & 0.0190 & 2.7 & 614 & 0.66 & 0.0252 & 2.6 \\
\hline \multicolumn{12}{|c|}{ Flavonols } \\
\hline Quercetin 3-rutinoside & 200 & 181 & 31.8 & 232 & 2313 & 0.0250 & 2.3 & 200 & 2.73 & 0.0073 & 0.2 \\
\hline Quercetin 3-galactoside & 80 & 263 & 12.9 & 99 & 3049 & 0.0260 & 2.4 & 80 & 2.02 & 0.0047 & 0.2 \\
\hline Quercetin 3-glucoside & 50 & 509 & 10.3 & 40 & 2086 & 0.0070 & 11.3 & 50 & 1.78 & 0.0029 & 0.2 \\
\hline \multicolumn{12}{|c|}{ Phenolic acids } \\
\hline Neochlorogenic acid & 98 & 157 & 15.6 & 98 & 1107 & 0.0165 & 1.9 & 80 & 6.68 & 0.0088 & 0.1 \\
\hline
\end{tabular}

$\mathrm{SE}$ - standard error; $q_{\mathrm{m}}$ is the Langmuir apparent maximum adsorption capacity of $\beta$-glucan (mg/g of $\beta$-glucan); $K_{\mathrm{L}}$ is the Langmuir equilibration constant of adsorption $(1 / \mathrm{mg}) ; q_{\mathrm{s}}$ is the theoretical saturation capacity or the maximum adsorption capacity of $\beta$-glucan (mg/g of $\beta$-glucan); $E$ is the adsorption mean free energy $(\mathrm{J} / \mathrm{mol}) ; c_{\mathrm{s}}$ is theoretical saturation concentration or solubility $(\mathrm{mg})$ for the given volume of solution; $q_{\mathrm{m}}$ is the Hill apparent maximum adsorption capacity ( $\mathrm{mg} / \mathrm{g}$ of $\beta$-glucan), $n_{\mathrm{H}}$ is the Hill cooperativity coefficient; and $K$ is the Hill constant (mg).

$q_{e}=\frac{q_{m} K_{L} c_{e}}{1+K_{L} c_{e}}$

where: $c_{\mathrm{e}}$ is the phenolic amount in the reaction solution at equilibrium (un-adsorbed phenolics) ( $\mathrm{mg}$ ); $q_{\mathrm{e}}$ is the amount of phenolic adsorbed per g of $\beta$-glucan at equilibrium $(\mathrm{mg} / \mathrm{g})$; $K_{\mathrm{L}}$ is the Langmuir equilibration constant of adsorption $(1 / \mathrm{mg})$; and $q_{\mathrm{m}}$ is the apparent maximum adsorption capacity of $\beta$-glucan (mg/g) [Soto et al., 2011]. All $q_{\mathrm{e}}$ and $c_{\mathrm{e}}$ for all phenolics were modeled with the Langmuir equation using the improved non-linear modelling. This enabled determining the parameters $q_{\mathrm{m}}$ and $K_{\mathrm{L}}$ (Table 2). The $q_{\mathrm{m}}$ represents the theoretical maximum adsorption capacity of a compound predicted with the model. The predicted $q_{\mathrm{m}}$ of two anthocyanins, cyanidin 3 -galactoside, and cyanidin 3-arabinoside were higher than that of cyanidin 3-xyloside and cyandin 3-glucoside (356, 350, 238 , and $100 \mathrm{mg} / \mathrm{g}$, respectively). In the flavonol subgroup, quercetin 3-rutinoside showed a higher predicted $q_{\mathrm{m}}$ than galactoside and glucoside of quercetin $(200,80$, and $50 \mathrm{mg} / \mathrm{g}$, respectively). Neochlorogenic acid had a predicted $q_{\mathrm{m}} 98 \mathrm{mg} / \mathrm{g}$. The predicted $q_{\mathrm{m}}$ values are in accordance with $q_{\mathrm{e}, \text { measured }}$. To visualize this, Figure 5 shows the correlation between the predicted, theoretical $q_{\mathrm{m}}$, and $q_{\text {e,measured }}$. A correlation was found between the measured values and those predicted by a model with the coefficient of determination $\left(\mathrm{r}^{2}\right)$ of 0.76 .

\section{Dubinin-Radushkevich isotherm}

This isotherm describes an adsorption that takes place on a heterogeneous surface of an adsorbent, and involves a pore filling mechanism [Al-Ghouti \& Da'ana, 2020]. It allows distinguishing between bonds involved in the adsorption (chemical or physical adsorption). The equation has already been mentioned as Eq. 3 [Hu \& Zhang, 2019]:

$q_{e}=q_{s} \exp \left(-\beta \varepsilon^{2}\right)$

The equation for the Polany potential $(\varepsilon)$ is:

$\varepsilon=R T \ln \left(\frac{c_{S}}{c_{e}}\right)$

By inclusion of this $\varepsilon$ in Equation 3, the Dubinin-Radushkevich equation becomes:

$q_{e}=q_{s} \exp \left(-\beta R^{2} T^{2}\left(\ln \left(\frac{c_{S}}{c_{e}}\right)\right)^{2}\right)$

where: $q_{\mathrm{s}}$ is the theoretical saturation capacity or the maximum adsorption capacity of $\beta$-glucan $(\mathrm{mg} / \mathrm{g}$ ); $\beta$ is a constant related to the adsorption energy $\left(\mathrm{mol}^{2} / \mathrm{J}^{2}\right) ; \varepsilon$ is the Polany potential $(\mathrm{J} / \mathrm{mol}) ; R$ is the gas constant $(8.314 \mathrm{~J} / \mathrm{mol} \mathrm{K})$; $T$ is the temperature $(\mathrm{K})$; and $c_{\mathrm{s}}$ is theoretical saturation concentration or solubility (mg) for the given volume of solution [Foo \& Hameed, 2010; Hu \& Zhang, 2019]. The experimental data $\left(q\right.$ and $\left.c_{\mathrm{e}}\right)$ were modeled using Equation 7 with the improved non-linear regression, and $q_{\mathrm{s}}, \beta$, and $c_{\mathrm{s}}$ were determined. The parameter $\beta$ was used to calculate the adsorption mean free energy $E(\mathrm{~J} / \mathrm{mol})$ using Equation 8 [Foo \& Hameed, 2010]:

$E=\frac{1}{\sqrt{2 \beta}}$ 
Finally, $q_{\mathrm{s}}, E$ and $c_{\mathrm{s}}$ predicted with the model were reported (Table 2). The $q_{\mathrm{s}}$ that represents the theoretical saturation capacity of $\beta$-glucan showed the highest value for cyanidin 3-galactoside and cyanidin 3-arabionside, followed by cyanidin 3-xyloside and cyanidin 3-glucoside (309, 269, 190, and $79 \mathrm{mg} / \mathrm{g}$, respectively). In the flavonol subgroup, the highest $q_{\mathrm{s}}$ was determined for quercetin 3-rutinoside, followed by quercetin 3-galactoside and quercetin 3-glucoside (232, 99, and $40 \mathrm{mg} / \mathrm{g}$, respectively). Neochlorogenic acid had $q_{\mathrm{s}}$ of $98 \mathrm{mg} / \mathrm{g}$. The $q_{\mathrm{s}}$ values predicted by the model followed the $q_{\text {e,measured }}$ (Figure 2). Namely, the compound with a higher $q_{\mathrm{e} \text {,measured }}$ also had a higher fitted $q_{\mathrm{s}}$ and vice versa. This can be better seen in a diagram that shows $q_{\mathrm{s}}$ vs $q_{\mathrm{e} \text {,measured }}$ (Figure 5). A high correlation was found between $q_{\mathrm{s}}$ and $q_{\mathrm{e} \text {,measured }}\left(\mathrm{r}^{2}=0.81\right)$, which indicates an agreement between the measured values and the predicted ones. Furthermore, the parameter $E$ predicted by the model, which represents an apparent mean free energy of adsorption, was lower than $8,000 \mathrm{~J} / \mathrm{mol}$ for most of the phenolics. This indicates a physical adsorption (physisorption) with the creation of non-covalent bonds like $\mathrm{H}$ bonds and Van der Waals forces, and agrees with earlier studies that suggested the physical adsorption between $\beta$-glucan and tea phenolics [Wu et al., 2011a,b], tannic acid and $\beta$-glucan [Li et al., 2019], phenolics and cellulose [Phan et al., 2016] and procyanidins and cell wall materials [Le Bourvellec et al., 2004]. In our study, only cyanidin 3-galactoside had an $E$ value higher than 8,000 J/mol.

\section{Hill isotherm}

The Hill isotherm describes an adsorption of different species onto a homogenous adsorbent [Al-Ghouti \& Da'ana, 2020], and allows suggesting whether the adsorption is cooperative or non-cooperative [Al-Ghouti \& Da'ana, 2020]. The already mentioned Hill isotherm equation (Eq. 4) is:

$q_{e}=\frac{q_{m} c_{e}^{n_{H}}}{K_{D}+c_{e}^{n_{H}}}$

where: $q_{\mathrm{m}}$ is the apparent maximum adsorption capacity $(\mathrm{mg} / \mathrm{g}), n_{\mathrm{H}}$ is the Hill cooperativity coefficient; and $K_{\mathrm{D}}$ is the Hill constant $\left(\mathrm{mg}^{\mathrm{nH}}\right)$ ) [Al-Ghouti \& Da'ana, 2020]. In fitting a Hill model, we find it to be numerically more stable to represent the Hill constant in the form $K_{\mathrm{D}}=K^{\mathrm{nH}}$. Expressed in this form $K$ is the half-max point (mg), corresponding to the value of $c_{\mathrm{e}}$ at which the Hill isotherm equation reaches half of its maximum value. From a stable fit to $K$ we can then find $K_{\mathrm{D}}$ from $K^{\mathrm{nH}}$ using the fitted cooperativity coefficient $n_{\mathrm{H}}$. All $q_{\mathrm{e}, \text { measured }}$ values were modeled with Hill equation, and parameters of the model were determined $\left(q_{\mathrm{m}}, n_{\mathrm{H}}\right.$ and $\left.K\right)$ (Table 2$)$. The parameter $q_{\mathrm{m}}$ which represents the predicted, theoretical maximum adsorption capacity was highest for cyanidin 3-xyloside, cyanidin 3-galactoside, and cyanidin 3-arabinoside (614, 554 , and $350 \mathrm{mg} / \mathrm{g}$ respectively), followed by cyanidin 3-glucoside $(100 \mathrm{mg} / \mathrm{g})$, in the anthocyanin subgroup. In the flavonol subgroup, it was the highest for quercetin 3-rutinoside, followed by quercetin 3-galactoside and quercetin 3-glucoside $(200,80$, and $50 \mathrm{mg} / \mathrm{g}$, respectively). Neochlorogenic acid had a $q_{\mathrm{m}}$ of $80 \mathrm{mg} / \mathrm{g}$. The correlation between predicted $q_{\mathrm{m}}$ and $q_{\mathrm{e} \text {,measured }}$ was not as high $\left(\mathrm{r}^{2}=0.34\right)$ as for Langmuir

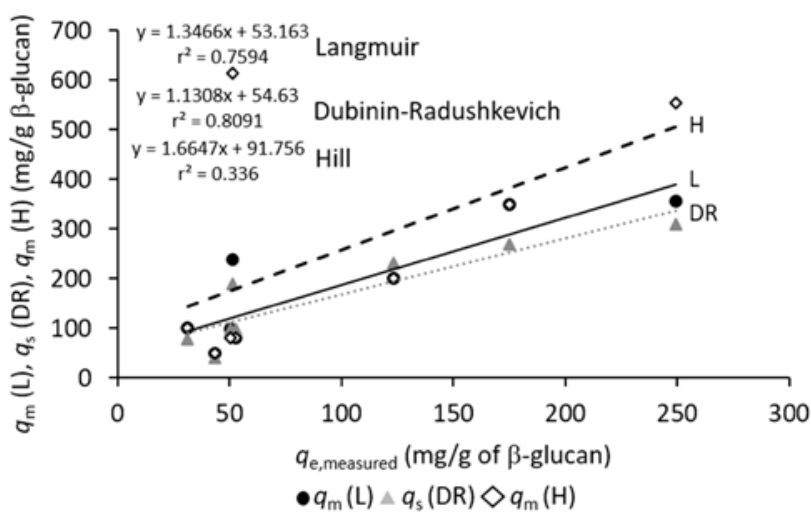

FIGURE 5. The correlation between predicted $q_{\mathrm{m}}$ from Langmuir (L), $q_{\mathrm{m}}$ from Hill $(\mathrm{H}), q_{\mathrm{s}}$ from Dubinin-Radushkevich (DR), and $q_{\mathrm{e} \text {,measured }}$ (mg/g of $\beta$-glucan). $q_{\mathrm{m}}$ is the Langmuir and Hill apparent maximum adsorption capacity of $\beta$-glucan ( $\mathrm{mg} / \mathrm{g}$ of $\beta$-glucan), $q_{\mathrm{s}}$ represents the Dubinin-Radushkevich theoretical saturation capacity or the maximum adsorption capacity of $\beta$-glucan (mg/g of $\beta$-glucan), $q_{\text {e,measured }}$ represents measured value of adsorption capacity ( $\mathrm{mg} / \mathrm{g}$ of $\beta$-glucan).

and Dubinin-Radushkevich (Figure 5). Hill's parameter $n_{\mathrm{H}}$ describes a cooperative or non-cooperative bonding. When $n_{\mathrm{H}}>1$, the bonding could be a positively cooperative bonding. In this case, when a molecule bonds to an adsorbent, other molecules can bond more easily. If $n_{\mathrm{H}}<1$, the bonding is a negatively cooperative bonding (already bonded molecule makes the bonding of other molecules more difficult). If $n_{\mathrm{H}}=1$, the bonding is non-cooperative, where bonding is independent of the molecules already bound to the adsorbent [Al-Ghouti \& Da'ana, 2020]. The bonding could be positively cooperated $\left(n_{\mathrm{H}}>1\right.$ for cyanidin 3 -glucoside, cyanidin 3-arabinoside; rutinoside, galactoside and glucoside of quercetin; neochlorogenic acid) but also negatively cooperated $\left(n_{\mathrm{H}}<1\right.$ for cyanidin 3-galactoside, cyanidin 3-xyloside).

\section{Principal component analysis (PCA)}

The results obtained were subjected to PCA. The adsorption capacity $\left(q_{\text {e,measured }}\right)$, the amount of phenolics in aronia, $n_{\mathrm{H}}$ and $E$, were chosen for PCA since they are important for the description of the adsorption process (Figure 6a). The following clustering of phenolic compounds according to their affiliation to a phenolic group can be suggested: anthocyanins, flavonols, and phenolic acids. Additionally, while performing PCA analysis, it became visible that $n_{\mathrm{H}}$ and $E$ could be parameters that might have contributed to that difference and affect the clustering. Indeed, the scatterplot of $n_{\mathrm{H}} v_{S} E$ (Figure 6b) shows that phenolic compounds are different according to $n_{\mathrm{H}}$ and $E$, and could be clustered according to their affiliation into a phenolic subgroup: flavonols, anthocyanins, and phenolic acids. Anthocyanins showed lower $n_{\mathrm{H}}$ and higher $E$ than flavonols and phenolic acids. In the anthocyanin subgroup, as $n_{\mathrm{H}}$ goes to lower values, from positive toward negative cooperation in bonding, $E$ becomes higher. Flavonols and phenolic acids have higher $n_{\mathrm{H}}$ for positive cooperation and lower $E$.

This behavior can be attributed to the chemical structure of phenolics. The aglycon in anthocyanin molecules is cyanidin, to which different glycosides are attached at 
a)

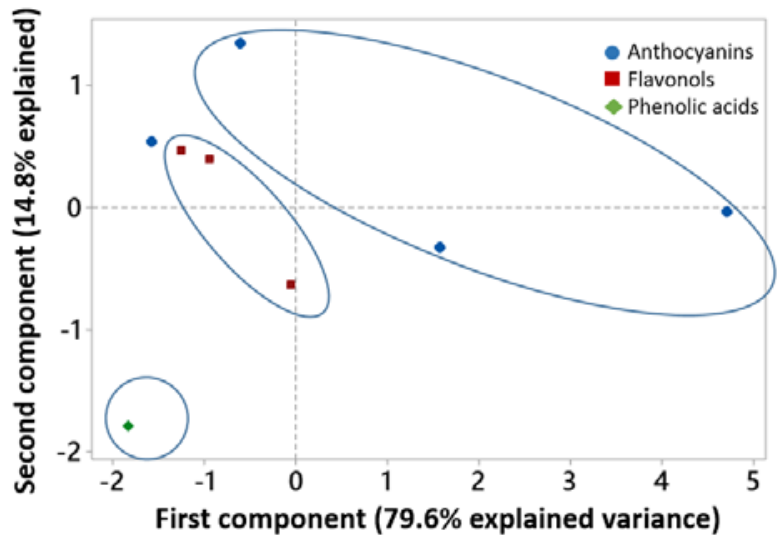

b)

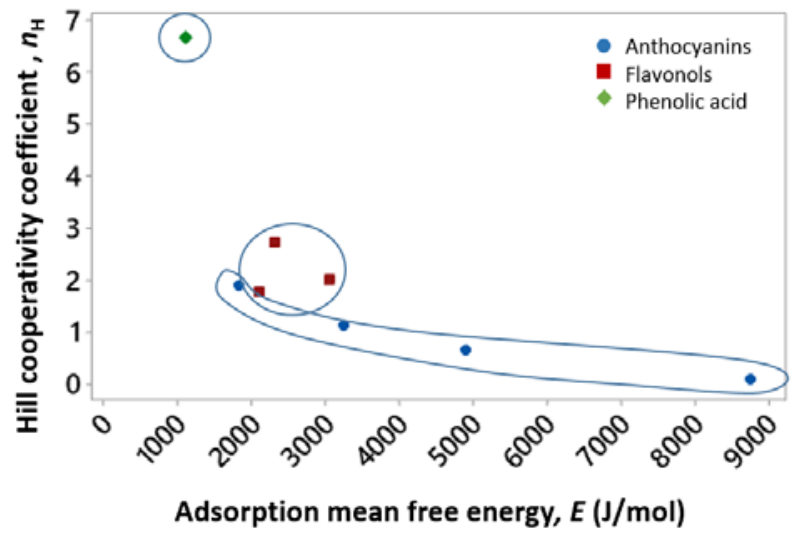

FIGURE 6. a) Principal component analysis of the measured value of adsorption capacity, $q_{\text {e,measured }}$ (mg/g $\beta$-glucan), content of individual phenolics in the extract (mg/kg fresh weight), Hill cooperativity coefficient, $n_{\mathrm{H}}$ and the Dubinin-Radushkevich adsorption mean energy, $E$ (J/mol). b) Scaterplott of $n_{\mathrm{H}}$ and $E(\mathrm{~J} / \mathrm{mol})$.

the $\mathrm{C} 3$ position of the $\mathrm{C}$ ring. At lower $\mathrm{pH}$, as in our study ( $\mathrm{pH} 1.5)$, cyanidin aglycon is present in the form of a flavylium cation which has an ionic nature. It has a positive charge at the oxygen atom of the $\mathrm{C}$ ring. The aglycon in quercetin derivatives is quercetin to which different glycosides are attached at the $\mathrm{C} 3$ position of the $\mathrm{C}$ ring. Quercetin does not have a charged atom. Furthermore, phenolic acid (neochlorogenic acid) is an acid and it changes the structure according to the $\mathrm{pH}$ value of the environment. At low $\mathrm{pH}(\mathrm{pH} 1.5)$, the neochlorogenic acid is in a protonated, nonionic form [Uranga et al., 2016], similar to flavonols. The bonding of anthocyanins onto $\beta$-glucan might be positively and then negatively cooperative, possibly due to the charged molecules. Namely, anthocyanin molecules can bond onto $\beta$-glucan, and once bonded (positive cooperation) they can repulse other molecules, which leads to more difficult bonding (a negative cooperation). And the adsorption mean free energy becomes higher. Flavonols and neochlorogenic acid are not charged at low $\mathrm{pH}$, and thus a cooperative bonding with higher $n_{\mathrm{H}}$ values could be suggested.

\section{CONCLUSION}

The adsorption data can be modeled with a novel nonlinear regression and this new approach gave lower SE than the standard non-linear modeling, with more precisely determined isotherm parameters. The experiments and modeling allowed us to suggest a description of the adsorption process. The bonds created between aronia phenolics and $\beta$-glucan could involve both $\mathrm{H}$ bonds and Van der Waals forces. $\mathrm{H}$ bonds could be created between $\mathrm{OH}$ groups of phenolics and $\beta$-glucan. Once $\mathrm{H}$ bonds are created, phenolics and $\beta$-glucan are closer, and Van der Waals attractive forces might additionally connect those molecules, as it was reported for the adsorption of tea phenolics onto $\beta$-glucan [Wu et al., 2011a,b]. Furthermore, at pH 1.5 as in our study, the $\mathrm{OH}$ groups of all phenolics and $\beta$-glucan are protonated (nonionic), which is a prerequisite for the formation of $\mathrm{H}$ bonds
[Li et al., 2019]. This fact also supports the formation of $\mathrm{H}$ bonds.

Phenolics from aronia have different chemical structures at $\mathrm{pH}$ 1.5. Those structural differences might have affected the adsorption. Namely, flavonols and neochlorogenic acid are in nonionic forms in comparison to ionic anthocyanins. After the adsorption of all these phenolics, ionic anthocyanins might have caused some repulsions, which hindered further bonding.

Since the adsorption was studied at low $\mathrm{pH}$ (1.5), it might be suggested that aronia phenolics can interact with $\beta$-glucan at the low $\mathrm{pH}$ of the digestive tract. That behavior might be important for carrying phenolics through the digestive tract by $\beta$-glucan. These findings need to be supported by additional studies of adsorption at different $\mathrm{pH}$ values and using in vitro simulated digestion processes. Furthermore, $\beta$-glucan has already been studied as a delivery system for single strain DNA [Hwang et al., 2018] or for doxorubicin molecules [Lee et al., 2019]. That is why, it might be suggested that it has the potential to serve as a natural delivery system for aronia phenolics.

\section{RESEARCH FUNDING}

This work has been fully supported by Croatian Science Foundation under the project HRZZ-IP-2016-06-6777 and project HRZZ-IP-2016-06-6545. The work of J.I. was financed by European social fund, Operational Program 2014-2020, aim 10.II.3.

\section{CONFLICT OF INTERESTS}

The authors declare no potential conflicts of interests.

\section{ORCID IDs}

A.R. Barron https://orcid.org/0000-0002-8072-7351

J. Ištuk https://orcid.org/0000-0002-0675-5784

L. Jakobek https://orcid.org/0000-0002-4846-327X

P. Matić https://orcid.org/0000-0003-0804-1280 


\section{REFERENCES}

1. Al-Ghouti, M.A., Da'ana, D.A. (2020). Guidelines for the use and interpretation of adsorption isotherm models: A review. Journal of Hazardous Materials, 393, art. no. 122383.

https://doi.org/10.1016/j.jhazmat.2020.122383

2. De Smet, R., Demoor, T., Verschuere, S., Dullaers, M., Ostroff, G.R., Leclerq, G., Allais, L., Pilette, C., Dierendonck, M., De Geest, B.G., Cuvelier, C.A. (2013). $\beta$-glucan microparticles are good candidates for mucosal antigen delivery in oral vaccination. Journal of Controlled Release, 172(3), 671-678.

https://doi.org/10.1016/j.jconrel.2013.09.007

3. Denev, P., Čiž, M., Kratchanova, M., Blazheva, D. (2019). Black chokeberry (Aronia melanocarpa) polyphenols reveal different antioxidant, antimicrobial and neutrophil-modulating activities. Food Chemistry, 284, 108-117.

https://doi.org/10.1016/j.foodchem.2019.01.108

4. Foo, K.Y., Hameed, B.H. (2010). Insight into the modeling of adsorption isotherm systems. Chemical Engineering Journal, 156(1), 2-10. https://doi.org/10.1016/j.cej.2009.09.013

5. Gao, R., Liu, H., Peng, Z., Wu, Z., Wang, Y., Zhao, G. (2012). Adsorption of (-)-epigallocatechin-3-gallate (EGCG) onto oat ß-glucan. Food Chemistry, 132(4), 1936-1943.

https://doi.org/10.1016/j.foodchem.2011.12.029

6. Hellström, J.K., Shikov, A.N., Makarova, M.N., Pihlanto, A.M., Pozharitskaya, O.N., Ryhänen, EL., Kivijärvi, P., Makarov, V.G., Mattila, P.H. (2010). Blood pressure-lowering properties of chokeberry (Aronia mitchurinii, var. Viking). Journal of Functional Foods, 2(2), 163-169.

https://doi.org/10.1016/j.jf.2010.04.004

7. Hu, Q., Zhang, Z. (2019). Application of Dubinin-Radushkevich isotherm model at the solid/solution interface: A theoretical analysis. Journal of Molecular Liquids, 277, 646-648.

https://doi.org/10.1016/j.molliq.2019.01.005

8. Hwang, J., Lee, K., Gilad, A.A., Choi, J. (2018). Synthesis of beta-glucan nanoparticles for the delivery of single strand DNA. Biotechnology and Bioprocess Engineering, 23, 144-149. https://doi.org/10.1007/s12257-018-0003-4

9. Jakobek, L. (2015). Interactions of polyphenols with carbohydrates, lipids and proteins. Food Chemistry, 175, 556-567. https://doi.org/10.1016/j.foodchem.2014.12.013

10. Jakobek, L., Buljeta, I., Ištuk, J., Barron, A.R. (2020a). Polyphenols of traditional apple varieties in interaction with barley $\beta$-glucan: a study of the adsorption process. Foods, 9(9), art. no. 1278. https://doi.org/10.3390/foods9091278

11. Jakobek, L., Matić, P, Kraljević, Š., Ukić, Š., Benšić, M., Barron, A.R. (2020b). Adsorption between quercetin derivatives and $\beta$-glucan studied with a novel approach to modeling adsorption isotherms. Applied Science, 10(5), art. no. 1637. https://doi.org/10.3390/app10051637

12. Kim, B., Ku, C.S., Pham, T.X., Park, Y., Martin, D.A., Xie, L., Taheri, R., Lee, J., Bolling, B.W. (2013). Aronia melanocarpa (chokeberry) polyphenol-rich extract improves antioxidant function and reduces total plasma cholesterol in apolipoprotein E knockout mice. Nutrition Research, 33(5), 406-413. https://doi.org/10.1016/j.nutres.2013.03.001

13. Le Bourvellec, C., Guyot, S., Renard, C.M.G.C. (2004). Non-covalent interaction between procyanidins and apple cell wall material Part I. Effect of some environmental parameters. Biochimica et Biophysica Acta, 1672(3), 192-202.

https://doi.org/10.1016/j.bbagen.2004.04.001

14. Le Bourvellec, C., Renard, C.M.G.C. (2005). Non-covalent interaction between procyanidins and apple cell wall material. Part II: Quantification and impact of cell wall drying. Biochimica et Biophysica Acta, 1725(1), 1-9.

https://doi.org/10.1016/j.bbagen.2005.06.003

15. Lee, K., Kwong, Y., Hwang, J., Choi, Y., Kim, K., Koo, HJ., Seo, Y., Jeon, H., Choi, J. (2019). Synthesis and functionalization of $\beta$-glucan particles for the effective delivery of doxorubicin molecules. ACS Omega, 4(1), 668-674.

https://doi.org/10.1021/acsomega.8b02712

16. Li, R., Zeng, Z., Fu, G., Wan, Y., Liu, X., McClemens, D.J. (2019). Formation and characterization of tannic acid/beta-glucan complexes: influence of $\mathrm{pH}$, ionic strength, and temperature. Food Research International, 120, 748-755. https://doi.org/10.1016/j.foodres.2018.11.034

17. Li, X., Cheung, P.C.K. (2019). Application of natural $\beta$-glucans as biocompatible functional nanomaterials. Food Science and $\mathrm{Hu}$ man Wellness, 8(4), 315-319.

https://doi.org/10.1016/j.fshw.2019.11.005

18. Limousin, G., Gaudet, J.P., Charlet, L., Szenknect, S., Barthès, V., Krimissa, M. (2007). Sorption isotherms: A review on physical bases, modeling and measurement. Applied Geochemistry, 22(2), 249-275.

https://doi.org/10.1016/j.apgeochem.2006.09.010

19. Liu, C., Ge, S., Yang, J., Xu, Y., Zhao, M., Xiong, L., Sun, Q. (2016). Adsorption mechanism of polyphenols onto starch nanoparticles and enhanced antioxidant activity under adverse conditions. Journal of Functional Foods, 26, 632-644.

https://doi.org/10.1016/j.jff.2016.08.036

20. Liu, D., Martinez-Sanz, M., Lopez-Sanchez, P., Gilbert, E.P., Gidley, M. J. (2017). Adsorption behavior of polyphenols on cellulose is affected by processing history. Food Hydrocolloids, 63, 496-507. https://doi.org/10.1016/j.foodhyd.2016.09.012

21. Mäkelä, N., Brinck, O., Sontag-Strohm, T. (2020). Viscosity of $\beta$-glucan from oat products at the intestinal phase of the gastrointestinal model. Food Hydrocolloids, 100, art. no. 105422. https://doi.org/10.1016/j.foodhyd.2019.105422

22. Palafox-Carlos, H., Ayala-Zavala, J.F., González-Aguilar, G.A. (2011). The role of dietary fiber in the bioaccessibility and bioavailability of fruit and vegetable antioxidants. Journal of Food Science, 76(1), R6-R15.

https://doi.org/10.1111/j.1750-3841.2010.01957.x

23. Phan, A.D.T., D’Arcy, B.R., Gidley, M.J. (2016). Polyphenolcellulose interactions: Effects of $\mathrm{pH}$, temperature and salt. International Journal of Food Science and Technology, 51 (1), 203-211. https://doi.org/10.1111/ijfs.13009

24. Phan, A.D.T., Flanagan, B.M., D’Arcy, B.R., Gidley, M.J. (2017). Binding selectivity of dietary polyphenols to different plant cell wall components: Quantification and mechanism. Food Chemistry, 233, 216-227.

https://doi.org/10.1016/j.foodchem.2017.04.115

25. Phan, A.D.T., Netzel, G., Wang, D., Flanagan, B.M., D'Arcy, B.R., Gidley, M.J. (2015). Binding of dietary polyphenols to cellulose: Structural and nutritional aspects. Food Chemistry 171, 388-396.

https://doi.org/10.1016/j.foodchem.2014.08.118 
26. Renard, C.M.G.C., Watrelot, A.A., Le Bourvellec, C. (2017) Interactions between polyphenols and polysaccharides: mechanism and consequences in food processing and digestion. Trends in Food Science and Technology, 60, 43-51.

https://doi.org/10.1016/j.tifs.2016.10.022

27. Saura-Calixto., F. (2011). Dietary fiber as a carrier of dietary antioxidants: an essential physiological function. Journal of Agricultural and Food Chemistry, 59(1), 43-49.

https://doi.org/10.1021/jf1036596

28. Sidor, A., Drożdżyńska, A., Gramza-Michałowska, A. (2019). Black chokeberry (Aronia melanocarpa) and its products as potential health-promoting factors - An overview. Trends in Food Science and Technology, 89, 45-60.

https://doi.org/10.1016/j.tifs.2019.05.006

29. Sosnowska, D., Podsędek, A., Redzynia, M., Kucharska, A.Z. (2018). Inhibitory effect of black chokeberry fruit polyphenols on pancreatic lipase -Searching for most active inhibitors. Journal of Functional Foods, 49, 196-204.

https://doi.org/10.1016/j.jff.2018.08.029

30. Soto, M.L., Moure, A., Domíniguez, H., Parajó, J.C. (2011). Recovery, concentration and purification of phenolic compounds by adsorption. A review. Journal of Food Engineering 105(1), 1-27. https://doi.org/10.1016/j.jfoodeng.2011.02.010
31. Tang, HY., Fang, Z., Ng, K. (2020). Dietary fiber-based colontargeted delivery systems for polyphenols. Trends in Food Science and Technology, 100, 333-348.

https://doi.org/10.1016/j.tifs.2020.04.028

32. Uranga, J.G., Podio, N.S., Wunderlin, D.A., Santiago A.N. (2016). Theoretical and experimental study of the antioxidant behaviors of 5-O-caffeoylquinic, quinic and caffeic acids based on electronic and structural properties. Chemistry Select, I, 4113-4120.

https://doi.org/10.1002/slct.201600582

33. Wu, Z., Li, H., Ming, J., Zhao, G. (2011a). Optimization of adsorption of tea polyphenols into oat $\beta$-glucan using response surface methodology. Journal of Agricultural and Food Chemistry, 59(1), 378-385.

https://doi.org/10.1021/jf103003q

34. Wu, Z., Ming, J., Gao, R., Wang, Y., Liang, Q., Yu, H., Zhao, G. (2011b). Characterization and antioxidant activity of the complex of tea polyphenols and oat $\beta$-glucan. Journal of Agricultural and Food Chemistry, 59(19), 10737-10746.

https://doi.org/10.1021/jf202722w 